\title{
24- Bir Tuva masalının Vladimir Y. Propp'un yapısal anlatı çözümleme yöntemine göre incelenmesi: “Ak-Sagış Kara-Sagış İyi Alışkı”
}

Tuğba SARIKAYA AKSOY ${ }^{1}$

APA: Sarıkaya Aksoy, T. (2021). Bir Tuva masalının Vladimir Y. Propp’un yapısal anlatı çözümleme yöntemine göre incelenmesi: "Ak-SagıŞ Kara-Sagış İyi Alışkı". RumeliDE Dil ve Edebiyat Araştırmaları Dergisi, (25), 378-393. DOI: 10.29000/rumelide.1037502.

\section{$\ddot{O} \mathbf{z}$}

Bu çalışmada Tuva Türklerinin sihirli-olağanüstü masallar kategorisine giren Ak-Sagış Kara-Sagış İyi Alışkı “Ak Sagış Kara Sagıș İki Kardeşler” masalı Vladimir Y. Propp’un yapısal anlatı çözümleme yöntemine göre incelenmiştir. Bu yöntem metin merkezli halkbilimi kuramlarının yapısal halkbilimi kuramı içinde yer almaktadır. V. Y. Propp 1928 yılında yayımladı̆̆ı Morfologiya Skazki "Masalın Biçimbilimi veya Masalların Morfolojisi” adlı eserinde masalları yapı özelliklerine göre inceleyerek masallarda "sabit” ve "değişken” unsurlar olduğunu ortaya koymuştur. Ona göre masalların sabit unsurları şahısların meydana getirdikleri hareketler veya aksiyonlardır. Propp bunlara "işlev" adını verir. Masal kahramanlarının işlevlerinin birbirinin aynısı olduğunu söyler. Bu yüzden Propp, işlevlerin bir masal kahramanından başka bir masal kahramanına aktarıldığı sonucuna varmıştır (Çobanoğlu, 2012). Propp, masallarda 31 sabit unsur (işlev) olduğunu belirtir. Masallardaki değişken unsurlar ise isimleri ve görevleri değişen yedi şahıstan oluşmaktadır. Çalışma için belirlenen sihirliolağanüstü bir Tuva masalının üç olay dizisi etrafında geliştiği görülmüştür. Bu masalda eksiklik, yaşlı kadın, hayvan, ağaç, su, ihanet, sayı, balbal, kötü ruh, çadır, yol, han, lama, fal bakma vb. motiflerin geçtiği belirlenmiştir. V. Y. Propp'un yöntemine göre yapılan incelemede Propp'un belirlediği işlevlerden yirmi tanesinin ortak olduğu tespit edilmiştir. Ayrıca üç olay dizisi içinde bazı geri dönüşler de mevcuttur. Bu durum Propp'un işlev sıralamasına uymamaktadır. Sonuçta bu masalın Propp yöntemiyle benzer ve farklı yönleri olduğunu söyleyebiliriz.

Anahtar kelimeler: Tuva Türkleri, masal, V. Y. Propp, işlev, motif

\section{The analysis of a Tuvan tale according to structural analysis method of Vladimir Y. Propp: “Ak-Sagış Kara-Sagıș İyi Alışkı”}

\begin{abstract}
In this study, Ak-Sagış Kara-Sagış İyi Alışkı "Ak Sagış Kara Sagış Two Brothers” which is in the category of magical-extraordinary tales of the Tuvan Turks have been examined according to structural analysis method of Vladimir Y. Propp. This method has fallen into the structural folklore theory of the text which centers around folklore theories. In Morfologiya Skazki "The Morphology of The Tales" which was published in 1928, V. Y. Propp had examined the structural properties of the tales and found out the presence of "fixed" and "variable" components in the tales. According to him, the fixed components of the tales are behaviors and actions that persons have carried out. Propp has named these as the term "function". He tells us that the functions of the tale characters are the same with each other. That is why, Propp has concluded that functions have been transferred from one tale character to another tale character (Çobanoğlu, 2012). He has specified 31 fixed functions in the tales.
\end{abstract}

Dr., Bağımsız Araştırmacı (Ankara, Türkiye), tsarikaya88@gmail.com, ORCID ID: 00oo-0oo2-6622-8783 [Araştırma makalesi, Makale kaylt tarihi: 26.10.2021-kabul tarihi: 20.12.2021; DOI: 10.29000/rumelide.1037502]

Adres | Address

RumeliDE Dil ve Edebiyat Araştırmalar Dergisi $\quad$ RumeliDE Journal of Language and Literature Studies

Osmanağa Mahallesi, Mürver Çiçeği Sokak, No:14/8 Osmanağa Mahallesi, Mürver Çiçeği Sokak, No:14/8

Kadıköy - ISTANBUL / TÜRKIYE 34714 Kadıköy - ISTANBUL / TURKEY 34714

e-posta: editor@rumelide.com e-mail: editor@rumelide.com,

tel: +90 505 7958124, +90 2167730616 phone: +90 505 7958124, +90 2167730616 
The variable components in the tales consist of seven persons whose names and tasks have changed. It was observed that a magical-extraordinary tales of the Tuvan Turks determined for the study have developed around three storylines. In this tale was determined lack, old woman, animal, tree, water, betrayal, number, balbal, evil spirit, tent, road, monarch, lama, fortune-telling etc. motifs. In the examination have been carried out according to V. Y. Propp, it was defined that twenty of the Propp's functions have been common. There are also some flashbacks within the three storylines. This situation haven't fit Propp's arrangement of functions. As a result, we can say that this tale has similarities and differences with the method of Propp.

Keywords: Tuvan Turks, tale, V. Y. Propp, function, motif

\section{Giriş}

$\mathrm{Bu}$ çalışmada Güney Sibirya Türk topluluklarından olan Tuva Türklerinin sihirli-olağanüstü masallarından Ak-Sagış Kara-Sagış İyi Alışkı "Ak Sagış Kara Sagış İki Kardeşler” masalı Vladimir Y. Propp'un yapısal anlatı çözümleme yöntemine göre incelenecektir. V. Y. Propp, masalları 1928 yılında yayımlanan Morfologiya Skazki "Masalın Biçimbilimi" adlı eserinde biçimbilimsel bir yöntem doğrultusunda incelemiştir. Propp, bu yöntemi tarihî-coğrafi yönteme tepki olarak ortaya koymuş ve tek bir masal tipinin varyantlarını karşılaştırmak yerine farklı masallardaki aynı göreve sahip unsurları ortaya çıkararak masalların yapısını belirlemiştir. Propp, masal incelemelerini tümdengelim yöntemiyle yapar. Bir masaldaki değişen ve değişmez değerleri belirler. Değişen değerler, adlar ve özel nitelikler; değişmeyen değerler ise kişilerin eylemleri yani işlevleridir.

Tuva masalları üzerine Türkiye'de kitap düzeyinde bir araştırma olmakla beraber, bu masalların masal biçimbilimi açısından incelendiği örnekler oldukça sınırlıdır. Kuzeydoğu grubu Türk lehçeleri (Altay, Hakas, Tuva, Saha, Şor vb.) dışındaki lehçelerde masalların biçimbilimi üzerine bazı çalışmalar yapılmıştır. Ancak belirtilen gruba ait Türk lehçelerinin masalları üzerine yapılan çalışmalar oldukça azdır. Bu çalışma ile Tuva Türklerine ait bir masalın Propp yöntemiyle incelendiğinde hangi sonuçlara ulaşılacağı merak konusu olmuştur ve bu sonuçların tespit edilmesi amaçlanmıştır. Yapılan inceleme sonucunda daha uzak bir lehçe olarak nitelendirebileceğimiz Tuva Türkçesiyle yazılmış bir masalın Propp yöntemiyle benzerliklerini ve farklılıklarını ortaya koymak daha önce bu alanda yapılan bir çalışma olmadığı için alana katkı sağlayacaktır.

Çalışmada öncelikle Rus, Tuvalı, Batılı ve Türk araştırmacılar tarafından Tuva halk masalları üzerine yapılan çalışmalardan ve Tuva Türklerinin masalcılık geleneğinden kısaca bahsedilecek; çalışmanın yöntemini oluşturan V. Y. Propp'un yapısal anlatı çözümleme yönteminin sabit ve değişken değerlerini oluşturan unsurlar verilecektir. Ardından Mehmet Aça'nın Tıva Halk Masalları adlı kitabından seçilen Ak-Sagış Kara-Sagış İyi Alışkı masalının olay örgüsü ve masalın içinde geçen motifler örneklerle tespit edilecek; adı geçen masal V. Y. Propp yöntemine göre incelenip olay dizilerinin kodları simgesel olarak gösterilecektir. Son olarak çalışmanın sonuna incelenen masalın Tuva Türkçesi ile yazılmış metni eklenecektir.

\section{Tuva Türklerinin masalcılık geleneği}

Güney Sibirya Türk topluluklarından olan Tuva Türklerinin sözlü edebiyat ürünleri 19. yüzyılın ikinci yarısından itibaren W. Radlov, G. N. Potanin, N. F. Katanov, F. Y. Kon gibi isimler tarafindan derlenip yayımlanmaya başlamıştır. Radlov ve Katanov, derledikleri Tuva masallarını hem Tuva Türkçesinde

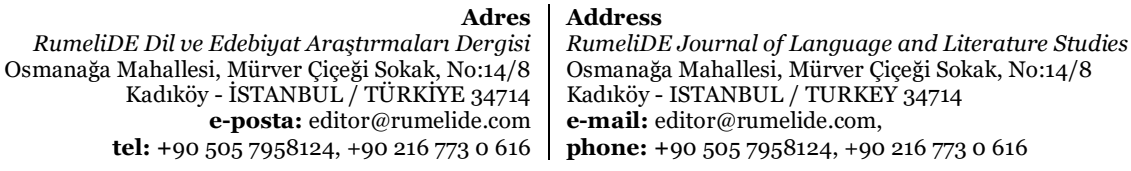


The analysis of a Tuvan tale according to structural analysis method of Vladimir Y. Propp: "Ak-Sagış Kara-Sagış İyi Alışkı" / T. Sarıkaya Aksoy (pp. 378-393)

hem de Rus dilinde yayımlarken; Potanin ve Kon ise sadece Rus dilinde yayım yapmışlardır. Tuva halk masalları üzerine yapılan çalışmalar daha çok derleme metinlerin yazıya geçirilmesi şeklindedir. Ayrıca masallar ile ilgili inceleme metinleri de bulunmaktadır.

Tuva halk masalları üzerine N. F. Katanov'un Barın-Hemçik ve Çer-Çarık arasında yaptığı derlemeler²; W. Radlov ve N. F. Katanov'un Güney Sibirya Türklerine ait yaptıkları derlemeler3, F. Y. Kon'un UlugHem, Kara-Hem, Bii-Hem, Toju ve Tandın bölgelerinde yaşayan Tuva Türklerinden yaptıkları folklor ve etnografya derlemeleri4 Rus araştırmacıların Tuva masalları üzerine yaptıkları ilk çalışmalardır.

1930 yılında Latin alfabesinin kabulüyle birlikte Tuva halk edebiyatı ürünlerinden halk şarkıları, atasözleri, bilmeceler, destanlar, masallar Tuva Türkçesinde derlenmiş ve yayımlanmıştır. A. Kalzan, O. Darıma, D. Kuular, M. Kök-ool, Ş. Sat, S. Sarıg-ool, L. Çadamba, K. Toyun, A. Palmbah, Y. Arançın, H. Seyfulin gibi isimler Tuva sözlü edebiyat metinlerini derleyen önemli şahsiyetlerdir5.

Tuvalı ve Rus araştırmacılar dışında Erika Taube ${ }^{6}$, Karl Reichl7, Kira Van Deusen ${ }^{8}$, K. David Harrison 9 gibi bazı Batılı araştırmacılar da Tuva masalları ve masal anlatma geleneği üzerine çalışmalar yapmışlardır. Türkiye'de ise Tuva masalları üzerine Reşit Rahmeti Arat'ın Radlov ve Katanov'un derleme eserinin çevirisi ${ }^{10}$, Nurettin Demir ${ }^{11}$ ve Mehmet Aça ${ }^{12}$ 'nın çalışmaları ilk olma özelliği taşımaktadır ${ }^{13}$.

Tuva sözlü edebiyatında hem masalı hem de destanı ifade etmek için tool terimi kullanılmıştır. Bu durum masal ve destan türünün birbirine karışmasına sebep olmuş ve Tuvalı araştırmacılar bu iki türü birbirinden ayırmak için destana maadırlıg tool "kahramanlık destanı" demişlerdir.

Tuva Türklerinin masalları üzerine yapılan incelemelerde masallar bazı araştırmalarda dirig amıtannar dugayında tooldar "hayvan masalları", huulgazın tooldar "sihirli-olağanüstü masallar" ve anaa tooldar "gerçekçi masallar" olarak sınıflandırılırken; bazı araştırmalarda bu sınıflandırmaya mögelig tooldar "kahramanlı masalları" ve distinçek bolgaş baştak tooldar "sıradan ya da komik masallar" da eklenmiştir (Samdan, 1994, s. 14-17; Taube, 1994, s. 54-280; Harrison, 2005, s. 1-4).

Tuva sözlü edebiyatında destan ve masal anlatıcılarına toolçu adı verilmiştir. Tuvalarda Ulug-Hem mektebi, Süt-Höl mektebi, Dzun-Hemçik mektebi ve Möygün-Tayga mektebi olmak üzere toolçuluk mektepleri vardır (Orus-ool, 1990, s. 3-4; Reichl, 2002, s. 63).

Katanov, N. F. (1903). Opıt İssledovaniya Uryanhayskogo Yazıka s Ukazniem Glavneyşih Rodstvennıh Otnoşeniy ego k Drugim Yazıkam Tyurkskogo Kornya. Kazan.

Radlov, V. V. (1866, 1907). Obraztsı Narodnoy Literaturı Turkskih Plemen. Birinci ve dokuzuncu ciltler. Petersburg.

Kon, F. Y. (1934). Za Pyatdesyat Let. Ekspeditsiya v Soyotiyu. C: 3. Moskva.

$\mathrm{Bu}$ araştırmacıların eserleri ve konuyla ilgili yapılan diğer çalışmalar için bk. Aça, M. (2007). Tiva Halk Masalları. Konya: Kömen Yayınları. 11-19.

Taube, E. (1978). Tuwinische Volksmärchen. Berlin.

Reichl, K. (1992). Turkic Oral Epic Poetry: Traditions, Forms, Poetic Structure. New York.

Deusen, K. V. (1996). Shyaan am! Tuvan Folk Tales. Bellingham.

Harrison, K. D. (2005). A Tuvan Hero Tale, with Commentory, Morphemic Analysis and Translation. Journal of American Oriental Society, Vol. 125, No: 1, 1-30.

Arat, R. R. (1994) (Çev.). Güney Sibirya Türkçesi Metinleri. Ankara.

Demir, N. (1997). Bir Tuva Masalının Türkiye Türkçesine Aktarılması. Sibirya Araştırmaları. 379-389.

Aça, M. (2007). Tiva Halk Masalları. Konya: Kömen Yayınları.

Bu bölümde belirtilen araştırmacılar Tuva halk masalları üzerine çalışmalar yapan ilk araştırmacılar olmaları bakımından önemlidir. Bu araştırmacıların çalışmalarından sonra yapılan bazı çalışmalar vardır. Ancak burada konuyu dağıtmamak adına sadece ilk çalışmalar verilmiştir.

RumeliDE Dil ve Edebiyat Araştırmalar Dergisi Osmanağa Mahallesi, Mürver Çiçeği Sokak, No:14/8 Kadıköy - İSTANBUL / TÜRKIYE 34714 e-posta: editor@rumelide.com tel: +90 $5057958124,+902167730616$
Address

RumeliDE Journal of Language and Literature Studies Osmanağa Mahallesi, Mürver Çiçeği Sokak, No:14/8

Kadıköy - ISTANBUL / TURKEY 34714

e-mail: editor@rumelide.com,

phone: +90 $5057958124,+902167730616$ 
Tuva Türklerinde toolçular genelde orta yaşlı ve yaşlı erkeklerden oluşur. Bunlar çoğunlukla okuma yazma bilmezler. Toolçuların çoğu tarım, hayvancılık ve balıkçlıkla uğraşırlar. Avcılar avlanmaya giderken yanlarında toolçular da götürürler. Avlandıktan sonra av hayvanlarını toolçularla eşit bir şekilde paylaşırlar. Toolçular hasta başlarında ve cenaze törenlerinde de destan ve masal anlatırlar. Toolçulara dinleyiciler tarafından hediyeler sunulur (Aça, 2007, s. 29-31<Samdan, 1994; Orus-ool, 1997).

\section{Vladimir Y. Propp’un yapısal anlatı çözümleme yöntemi}

Vladimir Yakovlieviç Propp göstergebilim, soybilim ve çeşitli anlatı çözümlemesi alanlarındaki çalışmalarıyla bilinen halk bilimi uzmanlarından biridir. Rus halk bilimcisi V. Y. Propp (1928) Leningrad’ta yayımlanan Morfologiya Skazki “Masalın Biçimbilimi” adlı eserinde olağanüstü masalları yapısalcı bir yöntemle incelemiştir. Propp, bu inceleme ile olağanüstü masalların kaynaklandığı temel yapıyı ortaya çıkarmıştır. Propp, çalışmasında A. N. Veselovski ve J. Bedier'in masal üzerine yaptı̆̆ 1 çalışmaları kendisine örnek almakla birlikte asıl kaynağı A. N. Afanasyev'in derlediği Rus Halk Masallar'ndaki 50-150 numaralar arasında yer alan yüz masal oluşturmaktadır (Dündar, 2002, s. 115; Çılak, 2005, s. 129).

V. Y. Propp, masallardaki "işlevsel" unsurları ortaya çıkarmayı ve halk masallarının yapısını belirleyen sabit yasaları tespit etmeyi amaçlamıştır. Masallar üzerine değerlendirme yapabilmek için masalın biçimbilimsel incelemesinin doğru bir şekilde yapılması gerekir (2001, s. 10).

V. Y. Propp, masalların sabit/değişmeyen ve değişken değerlerini saptamak için aşağıdaki durumları birbirleriyle karşlaş̧ırmıştır (2001, s. 38):

1. Kral, bir kahramana bir kartal verir. Kartal, kahramanı başka bir yere götürür.

2. Büyükbaba, Suçenko'ya bir at verir. At, Suçenko’yu başka bir yere götürür.

3. Bir büyücü, İvan'a bir kayık verir. Kayı, İvan’ı başka bir yere götürür.

4. Kraliçe, İvan’a bir yüzük verir. Yüzükten çıan iri yarı adamlar, İvan’ı başka bir yere götürür.

Örneklerde görüldüğü gibi şahısların adları ve sahip oldukları özel nitelikleri değişirken; yaptıkları eylemler yani işlevler değişmemektedir. Buradan masallarda çoğunlukla aynı eylemleri değişik kişilerin yaptı̆̆ sonucu çlkarılır. Bu eylemlere de "işlev" adı verilir ve bu işlevler masalın temelini oluşturan değişmez unsurlardır. Bu unsurların masallardaki yeri belirgin ve çok kesindir: 1. Şahısların işlevleri, nasıl gerçekleşirse gerçekleşsin, masalın değişmeyen, süreklilik gösteren öğeleridir. 2. İşlevlerin belli bir sayısı vardır. 3. İşlevlerin belli bir sırası vardır. 4. Bütün olağanüstü masallar, yapıları açısından tek bir özelliğe bağlanır (Propp, 2008, s. 24-26; 2011, s. 24-27).

V. Y. Propp, incelediği masallarda otuz bir işlev tespit etmiştiri14. Her bir işlevin içeriğinin özeti, tanımlaması ve düzenli karşılaştırmalar yapmayı sağlayan bir simgesi vardır. Masallar çoğunlukla bir başlangıç durumu ile başlar ve " $\alpha$ " simgesi ile gösterilir. İşlevler arasında bağlantıyı sağlayan öğeler “ $\$$ ” simgesi ile gösterilir. Başlangıç durumunun ardından diğer işlevler gelir. Bu işlevlerden uzaklaşma için " $\beta$ ”, yasaklama için " $\gamma$ ”, yasağ çiğneme için " $\delta$ ”, soruşturma için " $\varepsilon$ ", bilgi toplama için " $\zeta$ ", aldatma için

${ }_{14}$ V. Y. Propp’un masallar için belirlediği otuz bir işlev için bk. Propp ,V. Y. (2008). Masalın Biçimbilimi ve Olağanüstü Masalların Dönüşümleri (M. Rifat \& S. Rifat Çev.). İstanbul: Türkiye İş Bankası Kültür Yayınları. 29-65.

Adres | Address

RumeliDE Dil ve Edebiyat Araşttrmaları Dergisi $\quad$ RumeliDE Journal of Language and Literature Studies

Osmanağa Mahallesi, Mürver Çiçeği Sokak, No:14/8 $\quad$ Osmanağa Mahallesi, Mürver Çiçeği Sokak, No:14/8

Kadıköy - İSTANBUL / TÜRKIYE 34714 Kadıöy - ISTANBUL / TURKEY 34714

e-posta: editor@rumelide.com $\quad$ e-mail: editor@rumelide.com,

tel: +90 505 7958124, +90 216773 o 616 phone: +90 505 7958124, +90 216773 o 616 
" $\eta$ ”, suça katılma için " $\theta$ ”, kötülük için “A”, eksiklik için "a”, aracıllk için "B”, karşıt eylemin başlangıcı için "C", gidiş için “个”, bağış̧̧̧ şahsın ilk işlevi için "D", kahramanın tepkisi için "E”, sihirli nesnenin alınması için "F", iki yer arasında yolculuk için "G", çatışma için "H", özel bir işaret için "I", zafer kazanmak için “J”, kötülüğün giderilmesi için “K”, geriye dönüş için “ "’, izleme için “Pr”, yardım etmek için "Rs”, kahramanın kimliğini gizlemesi için "O", asılsız iddialar için "L", zor bir iş için "M", zor bir işi yerine getirme için "N", kahramanın tanınması için "Q", kimliğin ortaya çıkması için "Ex", şekil değiştirme için "T", cezalandırma için "U" ve evlenme için "Woo" simgeleri kullanılır (Propp, 2008, s. 29-65).

Yukarıda belirtilen işlevlerin her birinin kendisinden önce ve sonra gelen diğer bir işlevle bağlantılı olduğu görülür. Bu işlevlerin tamamı her masalda görülmese de işlevlerin sırası değişikliğe uğramaz (Çıblak, 2005, s. 132-133). Masalların çözümlenmesinde, masalı oluşturan olaylar dizisinin belirlenmesi önemlidir. Masalda karşılaşılan her yeni kötü olay, eksiklik, zarar yeni bir olay dizisini başlatır.

Propp’a göre masalda yer alan işlevler, yedi şahsın eylem alanına göre değişiklik gösterir: 1. Saldırgan şahsın eylem alanı (kötülük, izleme, çatışma), 2. Bağışçı şahsın eylem alanı (sihirli nesnenin kahramana verilmesi), 3. Yardımcı şahsın eylem alanı (yardım, zor işleri yerine getirme, kahramanın şekil değiştirmesi), 4. Aranan kişinin ve babasının eylem alanı (zor işleri yerine getirme, gerçek olmayan kahramanın ortaya çıkarılması, gerçek kahramanın tanınması, saldırgan şahsın cezalandırılması, evlenme), 5. Gönderen şahsın eylem alanı (kahramanın gönderilmesi), 6. Kahramanın eylem alanı (arayış amacıyla gidiş, bağış̧̧ı şahsın isteklerine tepki, evlenme), 7. Gerçek olmayan kahramanın eylem alanı (asllsız iddialar) (2001, s. 105-106).

Bu yöntemi Türkiye'de ilk kez Umay Günay, hazırladığı doktora tezinde Elazığ'dan derlenen 70 masal metni üzerinde uygulamıştır (Günay, 1975). Günay (1975) bu çalışmasında masalların tip numaralarını tespit etmiş, daha sonra bunları Propp yöntemine göre inceleyerek Propp’un tespit ettiği masal yapısının Türk masalları için de geçerli olduğu sonucuna varmıştır. Bu yöntem sadece masallar için değil farklı araştırmacılar tarafından farklı anlatı türlerine de uygulanmıştır: Gürdal, 1994; Dündar, 2002; Çıblak, 2005; Erol, 2005; Temel, 2005; Feyzioğlu, 2012; Şimşek, 2012; Abalı, 2013; Türker, 2013; Zariş, 2013; Bars, 2014; Ölmez, 2015; Yalçınkaya, 2015; Koçak \& Kurtlu, 2016; Başaran \& Çalışkan, 2017; Güman, $2021 \mathrm{vb}$.

Propp yönteminin daha çok Türkiye Türkçesi masalları ve diğer anlatı türlerine uygulandığı görülmektedir. Bu çalışmada Sibirya grubu Türk lehçelerinden olan Tuva Türklerine ait bir halk masalının bu yöntem doğrultusunda incelenip hangi sonuçlara ulaşılacağı görülecektir.

\section{Ak-Sagış Kara-Sagış İyi Alışkı “Ak-Sagış Kara Sagış Kardeşler” masalı}

Tuva Türklerinin sözlü edebiyat ürünlerinden olan halk masallarını kahramanlık, sihirli-olağanüstü, sosyal ya da gerçekçi, hayvan ve sıradan ya da komik masallar olarak sınıflandırabiliriz. Bu çalışmada Tuva Türklerinin sihirli-olağanüstü masallarından biri olan Ak-Sagış Kara-Sagış İyi Alışkı "Ak-Sagış Kara Sagış Kardeşler” masalı V. Y. Propp yöntemine göre incelenecektir. Adı geçen masal birden fazla olay dizisine sahip olduğu için masal devam ederken zaman zaman geri dönüşlerin olduğu görülmüştür. Bu yüzden Propp yöntemine göre incelenecek olan bu masalın olay örgüsü çerçevesinde farklı bir yönünün ortaya çıkması öngörülmüş ve bu masal seçilmiştir.

\footnotetext{
\begin{tabular}{r|l} 
Adres & Address \\
RumeliDE Dil ve Edebiyat Araştırmaları Dergisi & RumeliDE Journal of Language and Literature Studies
\end{tabular} Osmanağa Mahallesi, Mürver Çiçeği Sokak, No:14/8 Osmanağa Mahallesi, Mürver Çiçeği Sokak, No:14/8 Kadıköy - ISTANBUL / TURKIYE 34714 Kadıköy - ISTANBUL / TURKEY 34714 e-posta: editor@rumelide.com e-mail: editor@rumelide.com, tel: +90 505 7958124, +90 2167730616 phone: +90 505 7958124, +90 2167730616
} 


\subsection{Ak-Sagış Kara-Sagış İyi Alsşkı masalının olay örgüsü}

\section{Birinci olay dizisi:}

1. Ak-Sagış ve Kara-Sagış adlı iki kardeş ve bunların bir de yaşlı anneleri vardır.

2. Yaşlı anne ölür.

3. Kara-Sagış annesinin vasiyetini yerine getirmez, Ak-Sagış ise annesinin vasiyetini yerine getirerek onu istediği yere gömer.

4. Ak-Sagış annesini gömdükten sonra obasına geri döndüğünde kardeşi Kara-Sagış’ı obasında otururken bulur. İki kardeş yurtlarında yaşayıp giderler.

\section{İkinci olay dizisi:}

5. Kara-Sagış karnını doyurmak için kardeşinin hayvanlarını öldürüp yer ve sonra kardeşinin hayvanları tükenir.

6. Ak-Sagış’n hayvanları tükenince o da kardeşine senin hayvanlarını yiyelim der; ancak Kara-Sagış buna razı gelmez ve ona hiçbir şeyini vermeden gider.

7. Ak-Sagış da karnını doyurmak için oba oba gezmeye başlar.

8. Bir yerde karşısına bir çadır çıkar ve çadırın içinde üç yatak vardır. Ak-Sagış üç yatağın ortasına çukur kazıp yatar. Yatarken kurt, tilki ve ayı gelip konuşmaya başlarlar.

9. Kurt, tilki ve ayı birbirlerine ne yiyip içtiklerini anlatırlar ve sonra oradan uzaklaşırlar. (Hayvanların konuştukları şeyler Ak-Sagış’n hayatta kalması ve mutlu olması için önemlidir).

10. Ak-Sagış da hayvanların söylediği sözler doğrultusunda Karatı-Haan’a gelir.

11. Han, Ak-Sagış’a kızının hasta olduğunu, kemik falına bakmasını ve eğer onu iyileştirirse kendisini damadı yapacağını söyler.

12. Ak-Sagış kızın iyileşmesine vesile olur ve han onu damadı yapar.

13. Han, Ak-Sagış’a hayvanlarının öldüğünü ve tekrar kemik falına bakmasını söyler. Ak-Sagış hayvanların iyileşmesine de vesile olur.

14. Ak-Sagış ile Karatı-Haan birlikte yaşayıp giderler.

\section{Üçüncü olay dizisi:}

15. Kara-Sagış kendi hayvanlarını yiyip yoksullaşınca kardeşi Ak-Sagış’ı aramaya çıkar ve onu bulur.

16. Ak-Sagış kardeşine balbalını verip bununla yaşamasını söyler. Ancak kardeşine balbalı taşımak zor geldiği için Kara-Sagış balbalı kırar. Balbalın içinden altın, gümüş çımaz.

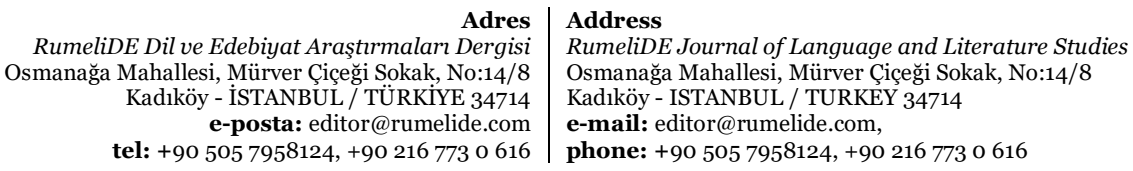


17. Kara-Sagış yeniden Ak-Sagış’n yaşadığı obaya gelir.

18. Ak-Sagış kardeşine balbalının nerede olduğunu sorar, kardeşinin balbalı kırdığını öğrenince kendisinin ne kadar kötü bir adam olduğunu söyler ve onun iyi bir şeyler duyması için onu obanın batı tarafındaki çadıra gönderir.

19. Kara-Sagış, daha önce Ak-Sagış’ın yattığı, içinde tilki, kurt ve ayının olduğu çadıra girer.

20. Tilki, kurt ve ayı konuşmaya başlarlar. Ancak onların konuşmaları Kara-Sagış için hiç iyi olmaz.

21. Bu üç hayvan çadırda Kara-Sagış’ı fark edince onu yerler.

22. Son olarak Ak-Sagış ve Karatı-Haan mutlu mesut bir şekilde yaşayıp giderler.

\subsection{Ak-Sagış Kara-Sagış İyi Alışkı masalının motifleri}

Motif, destan ve masal gibi anlatıların incelenmesinde olduğu gibi tekrarlanan, tipik bir olay örgüsüne sahip, anlatıcı, anlatım, dinleyici gibi temel unsurlara göre şekillenen, anlatıcının anlatımını sürdürmesinde ve dinleyicinin ilgisinin canlı tutulmasında önemli bir yeri olan anlatım tutumu ve imajlardır. Motif, masal anlatı türünde geleneklerde yaşayan ve konuyu belirleyen yapısal özelliklerdir (Ateş, 1996, s. 244; Aça, 2007, s. 99).

Tuva Türklerinin sihirli-olağanüstü masallarından biri olan Ak-Sagış Kara-Sagış İyi Alışkı masalının motiflerini aşağıdaki gibi gösterebiliriz:

1. Eksiklik motifi (İki kardeşin annelerinin ölümü)

2. Yaşlı kadının vasiyeti motifi (İki kardeşin anneleri ölünce yaşlı kadın defnedileceği yeri vasiyet eder)

3. Balbal motifi (Ak-Sagış’ın annesini gömdüğü yerde bulunan bir mezar taşı)

4. Kötü ruh motifi (Ak-Sagış’ın annesini gömdüğü yerde ortaya çıkar)

5. Hayvan motifi (Ak-Sagış ve Kara-Sagış kardeşlerin birçok hayvanı vardır)

6. Çadır motifi (Ak-Sagış kendisine yiyecek bulmak için yola çıktığında karşısına bir çadır çıkar)

7. Yol ve yolculuk motifi (Ak-Sagış ve Kara-Sagış kardeşlerin masal boyunca bir yerden başka bir yere gittikleri görülür)

8. Han motifi (Karatı-Haan, Ak-Sagış'a yardım eden iyi niyetli bir tiptir)

9. Ağaç motifi (Çam ağacı: Karatı-Haan’ın kızının bileziğini düşürdüğü yer; sedir ağacı: obadaki ağaçlardan biri)

10. Lama, kam motifi (Karatı-Haan’ın hastalanan kızı için dua ederler)

11. Yardımcı hayvanlar motifi (Kurt, tilki ve ayı Ak-Sagış’a iyilik ederken; Kara-Sagış’a kötülük ederler)

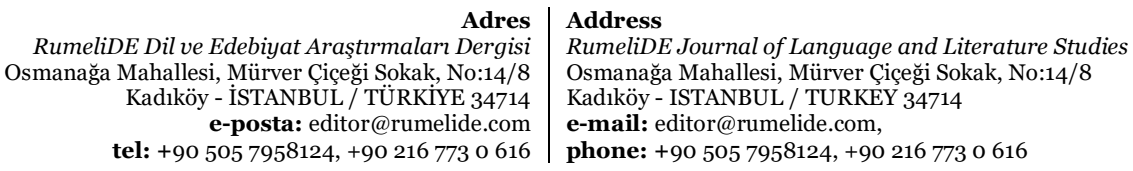


12. Fal bakma (kemik falı, kürek falı) motifi (Karatı-Haan kızı ve hayvanları için Ak-Sagış’a kemik ve kürek falı baktırır)

13. Yerine getirilmesi zor görevler motifi (Karatı-Haan kızını ve hayvanlarını iyileştirmesi için Ak-Sagış’a görev verir)

14. Su motifi (Karatı-Haan’ın hayvanlarının su içtiği yer)

15. İhanet motifi (Kara-Sagış, Ak-Sagış’ın verdiği balbalı kırar)

16. Hayvanların konuşması motifi (Tilki, kurt ve ayının konuşması)

17. Kötünün cezalandırılması motifi (Kurt, tilki ve ayı kötü kalpli Kara-Sagış’ı yiyerek onu cezalandırır)

18. Sayı motifi (üç hayvanın olması, üç yatağın olması)

19. Bitiş motifi (Ak-Sagış ve Karatı-Haan’ın kızı evlenir; hep birlikte mutlu mesut yaşarlar)

\subsection{Vladimir Y. Propp Yöntemine Göre Ak-Sagış Kara-Sagış İyi Alışkı Masalının İncelenmesi}

\section{Birinci olay dizisi:}

1. Masalda iki kardeş ve yaşlı anneleri vardır (tanımı: başlangıç durumu; simgesi $\alpha$ ).

2. Bu kardeşlerin anneleri vefat eder (tanımı: uzaklaşma; simgesi $\beta$ ).

3. Kara-Sagış annesini gömmeden yolun yarısından geri döner (tanımı: yasağı çiğneme; simgesi $\delta$ ).

4. Ak-Sagış annesini gömüp tekrar yola koyulur ve bir balbalın dibine yatar (bağlantı öğesi §).

5. Gece kötü ruh gelip balbal ile kavga eder ve ona annesini alacağını söyler (tanımı: aldatma; simgesi $\eta)$.

6. Ak-Sagış sabah olunca balbalın dibinden kalkıp obasına geri döner (tanımı: geri dönüş; simgesi $\downarrow$ )

\section{İkinci olay dizisi:}

7. Kara-Sagış kardeşinin hayvanlarını yiyerek bitirir (tanımı: kötülük; simgesi A).

8. Ak-Sagış’n bütün hayvanları biter (tanımı: eksiklik; simgesi a).

9. Ak-Sagış, yiyecek bulmak için balbalını yüklenip yola çıkar (tanımı: karşıt eylemin başlangıcı; simgesi C).

10. Ak-Sagış yürürken bir çadıra denk gelir ve içine girer (tanımı: gidiş; simgesi $\uparrow$ ).

11. Ak-Sagış çadırda yatarken kurt, tilki ve ayı konuşmaya başlarlar (tanımı: bağışçının ilk işlevi; simgesi D).

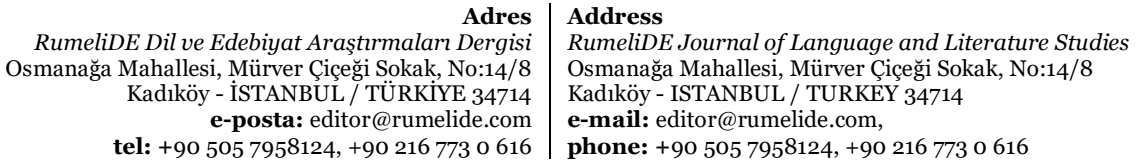


12. Ak-Sagış hayvanların konuşmalarından sonra Karatı-Haan’a gelir (tanımı: kahramanın tepkisi; simgesi E).

13. Han, Ak-Sagış’tan hasta olan kızı için kemik falına bakmasını ve onu iyileştirmesini ister (tanımı: zor iş; simgesi M).

14. Ak-Sagış, hanın kızını iyileştirir (tanımı: zor işi yerine getirme; simgesi N).

15. Ak-Sagış, hanın kızını iyileştirmek için girişimde bulununca bütün oba onu tanır (tanımı: tamı(n)ma; simgesi Q).

16. Ak-Sagış, hanın kızıyla evlenir (tanımı: evlenme; simgesi $\mathrm{W}^{\circ} \mathrm{o}$ ).

\section{(Geri dönüş)}

17. Hanın bütün hayvanları ölür ve her yer pislik içindedir (tanımı: eksiklik; simgesi a)

18. Han, Ak-Sagış’tan hayvanlarını kurtarması için yeniden kemik falına bakmasını ister (tanımı: zor iş; simgesi M).

19. Ak-Sagış, hanın hayvanlarını iyileştirir (tanımı: zor işi yerine getirme; simgesi N).

20. Ak-Sagış ve Karatı-Haan birlikte yaşayıp giderler (tanımı: zafer; simgesi J)

\section{Üçüncü olay dizisi:}

21. Kara-Sagış, kendi hayvanları bitince Ak-Sagış’ı aramaya çıkar (tanımı: uzaklaşma; simgesi $\beta$ ).

22. Kara-Sagış, kardeşinin nerede olduğunu bulmak için birilerine sorar (tanımı: soruşturma; simgesi $\varepsilon)$.

23. Kara-Sagış, kardeşinin yaşadığı obayı bulur. Ak-Sagış, Kara-Sagış'a bir balbal verip onu oradan uzaklaştırır (tanımı: aracılık, geçiş anı; simgesi B).

24. Kara-Sagış, kardeşinin verdiği balbalı kırarak Ak-Sagış’ın obasına gelir (tanımı: karşıt eylemin başlangıcı; simgesi C).

25. Kara-Sagış ağır balbalı taşımak istemediği için balbalı kırar (tanımı: bağışçının ilk işlevi; simgesi D).

26. Ak-Sagış, kardeşine balbalının nerede olduğunu sorar (tanımı: kahramanın tepkisi; simgesi E).

27. Ak-Sagış, kardeşinin iyiliği için onu batı tarafındaki bir çadıra gönderir (tanımı: iki krallık arasında yolculuk, bir kulavuz eşliğinde yolculuk; simgesi G).

\section{(Geri dönüş)}

28. Kara-Sagış kardeşinin söylediği çadırı bulur ve içine girer (tanımı: gidiş; simgesi $\uparrow$ ).

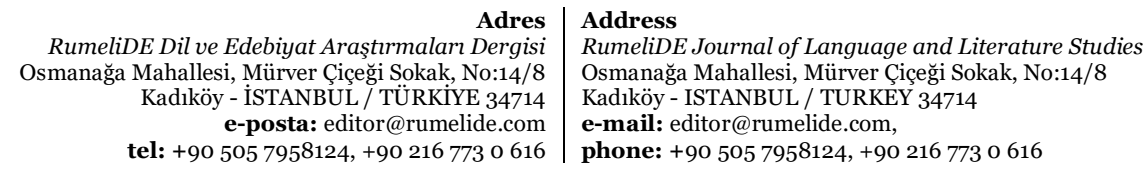


29. Kara-Sagış çadırda yatarken kurt, tilki ve ayı konuşmaya başlarlar (tanımı: bağışçının ilk işlevi; simgesi D).

30. Kurt, tilki ve ayı konuşmalarıyla Kara-Sagış’ı tuzağa düşürürler (tanımı: aldatma; simgesi ๆ).

31. Hayvanlar, konuşmalarıyla kötü kalpli Kara-Sagış’ cezalandırır (tanımı: cezalandırma; simgesi U).

32. Ak-Sagış ve Karatı-Haan birlikte mutlu mesut yaşayıp giderler (tanımı: zafer; simgesi J).

\section{Sonuç}

Güney Sibirya grubu Türk lehçeleri içinde yer alan Tuva Türklerinin sihirli-olağanüstü masallarından biri olan Ak-Sagış Kara-Sagış İyi Alışıı "Ak-Sagış Kara-Sagış Kardeşler” masalı üç olay dizisinden meydana gelmiştir. Birinci olay dizisi iki kardeşin annelerinin ölümüyle başlar. Ak-Sagış ve Kara-Sagış kardeşler annelerini gömmeye giderken Kara-Sagış daha fazla dayanamaz ve annesini gömmeden geri döner. Ak-Sagış ise annesinin vasiyetini yerine getirerek onu gömüp obasına döner ve birinci olay dizisi sonlanir.

İkinci olay dizisi Kara-Sagış’ın kardeşinin hayvanlarını yiyerek bitirmesi ile başlar ve bir eksiklik durumu oluşur. Ak-Sagış’ın yiyecek bulmak için yola çıkması, yolda bir çadıra denk gelmesi, çadırda yatarken kurt, tilki ve ayının konuşmaları ile Karatı-Haan'ın yanına gidip hanın kızını iyileştirmesi, onunla evlenmesi ve hep birlikte yaşamaları sonucunda kahramanın eksikliği tamamlanır ve ikinci olay dizisi sona erer.

Üçüncü olay dizisi ise Kara-Sagış’ın yiyeceği bitince Ak-Sagış’ı aramaya çımasıyla başlar. Ak-Sagış kardeşinin iyiliği için ona yardımcı olmaya çalışır. Ancak Kara-Sagış o kadar kötü kalplidir ki kardeşinin yardımlarına yüz çevirir ve sonunda kurt, tilki ve ayının yemi olur. Kötü kalpli kahramanın masaldan çlkmasıyla iyi kalpli Ak-Sagış ve Karatı-Haan birlikte mutlu mesut yaşayıp giderler ve üçüncü olay dizisi de sona erer.

Bu masaldaki üç olay dizisi aşağıdaki gibi kodlanabilir:

Birinci olay dizisi: $\alpha \beta \delta \eta \downarrow$

\section{İkinci olay dizisi: $\mathrm{AaC} \uparrow \mathrm{DEMNQW^{ \circ }}{ }^{\circ} \mathrm{aMNJ}$}

\section{Üçüncü olay dizisi: $\beta \varepsilon B C D E G \uparrow D \eta U J$}

V. Y. Propp'un yapısal anlatı çözümleme yöntemine göre incelenen bu masalda yirmi işlevin ortak olduğu tespit edilmiştir: $\alpha, \beta, \delta, \eta, \downarrow, \mathrm{B}, \mathrm{A}, \mathrm{a}, \mathrm{C}, \uparrow, \mathrm{D}, \mathrm{E}, \mathrm{M}, \mathrm{N}, \mathrm{Q}, \mathrm{W}^{\circ} \mathrm{o}, \mathrm{J}, \varepsilon, \mathrm{G}, \mathrm{U}$. Propp’un tespit ettiği otuz bir işlevden on bir tanesi bu masalda görülmemektedir: $\gamma, \zeta$, F, H, I, K, Pr, Rs, L, Ex, T.

V. Y. Propp, incelediği masallarda tespit ettiği işlevlerin sıralamasında bir değişiklik gözlenmeyeceğini belirtir. Ancak, incelenen bu Tuva masalının ikinci ve üçüncü olay dizilerinde masal normal seyrinde devam ederken işlevlerin sıralamasında bazı geri dönüşler olduğu tespit edilmiştir. Bu durumda Propp’un incelemesi dışında bir olay dizisi olduğu görülmektedir.

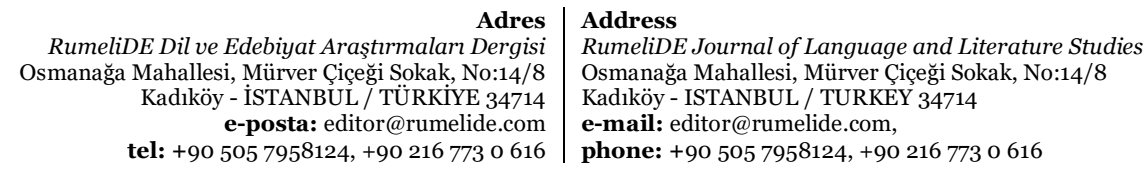


İncelenen masalda değişken unsurlar olarak belirlenen şahısların eylem alanlarına bakıldığında saldırgan ve gerçek olmayan kahramanın Kara-Sagış; yardımcı kahramanların Karatı-Haan ve hayvanlar (kurt, tilki ve ayı); aranan kişinin Karatı-Haan'ın kızı Aldın Çungulak prenses; kahramanın Ak-Sagış olduğu; bağışşı ve göndericinin bu masalda yer almadığı tespit edilmiştir.

Farklı lehçelerden ve masal dışındaki diğer anlatı türleri üzerine yapılacak incelemeler doğrultusunda sonuçlar daha da zenginleşecek ve bunları karşılaştırma imkânı doğacaktır.

\section{Kaynakça}

Abalı, İ. (2013). Yapısal Folklor Kuramı Bağlamında Bir Masal İncelemesi Örneği. İdil, 2(8), 26-40.

Aça, M. (2007). Tiva Halk Masalları. Konya: Kömen Yayınları.

Arat, R. R. (1994) (Çev.). Güney Sibirya Türkçesi Metinleri. Ankara.

Ateş, Ş. (1996). Hesse'nin Masalları: Motifler Otobiyografik Unsurlar. Bilig-1. Bahar. 244-249.

Bars, M. E. (2014). Vladimir Propp’un Yapısal Çözümleme Yöntemi Çerçevesinde "Battal Gazi Destanı" Filminin İncelenmesi. Tarih Okulu Dergisi (TOD), 7(XVIII), 79-97.

Başaran, C. B. \& Erol Çalışkan, Ş. S. (2017). Vladimir Propp’un Biçimbilimsel Yaklaşımından Hareketle Yozgat'tan Derlenmiş “Ercin Masalı” Üzerine Bir İnceleme. Uluslararası Sosyal Araştırmalar Dergisi, C: 10, S: 50, 49-55.

Çıblak, N. (2005). V. Propp'un Masal Çözümleme Metodu. Türk Dili, 638, 127- 140.

Çobanoğlu, Ö. (2012). Halk Bilimi Kuramları ve Araştırma Yöntemleri Tarihine Giriş. (6. Baskı). Ankara: Akçağ Yayınları.

Demir, N. (1997). Bir Tuva Masalının Türkiye Türkçesine Aktarılması. Sibirya Araştırmaları. 379-389.

Deusen, K. V. (1996). Shyaan am! Tuvan Folk Tales. Bellingham.

Dündar, H. (2002). Vladimir Propp ve Masalın Biçimbilimi. Milli Folklor, C. 7, S. 55, 115-118.

Erol, G. (2005). Vladimir Propp'un Biçimbilimsel Yaklaşımı Çerçevesinde Cesur Yürek Filminin İncelenmesi. İstanbul Üniversitesi İletişim Fakültesi Dergisi, 23, 353-361.

Feyzioğlu, N. (2012). On Erzurum Türküsü Üzerinde Bir Metot Denemesi. Atatürk Üniversitesi Sosyal Bilimler Enstitüsü Dergisi, 16(1), 187-198.

Güman, S. (2021). Olağanüstü Masal Örneği Olarak Terry Gilliam Sineması: Masalsı Bir Anlatım Sunan Filmlerin Propp Yöntemine Göre Analizi (Tez No. 682653) [Yüksek Lisans Tezi, Çankırı Karatekin Üniversitesi].

Günay, U. (1975). Elazığ Masalları (İnceleme). Erzurum: Atatürk Üniversitesi Basım Evi.

Gürdal, C. (1994). Propp Metodunun Rastgele Alınan Dört Türküden Hareketle Türk Halk Müziği Araştırmalarında Uygulanması Üzerine Bir Deneme. Millî Folklor, 23, 53-55.

Harrison, K. D. (2005). A Tuvan Hero Tale, with Commentory, Morphemic Analysis and Translation. Journal of American Oriental Society, Vol. 125, No: 1, 1-30.

Katanov, N. F. (1903). Opıt İssledovaniya Uryanshayskogo Yazıka s Ukazaniem Glavneyşih Rodstvennıh Otnoşeniy ego k Drugim Yazıkam Tyurkskogo Kornya. Kazan.

Koçak, B. \& Kurtlu, Y. (2016). Erzurum Halk Masallarından Üç Turunçlar Masalı’nın Vladimir Propp’un Yapısal Anlatı Çözümleme Yöntemine Göre İncelenmesi. Turkish Studies, Vol: 11/15 · 327-346.

Kon, F. Y. (1934). Za Pyatdesyat Let. Ekspeditsiya v Soyotiyu. C: 3. Moskva.

Orus-ool, S. M. (1990). Ege Çüül. Tıva Maadırlıg Tooldar, C. 1, Kızıl. 3-12.

Orus-ool, S. M. (1997). Tuvinskie Geroiçeskie Skazaniya. Tuvinskie Geroiçeskie Skazaniya Hunan Kara Boktug-Kiriş, Bora-Şeeley. Moskva. 10-38.

\footnotetext{
RumeliDE Dil ve Edebiyat Arasturmalar Adres $\mid$ Address

RumeliDE Dil ve Edebiyat Araştırmaları Dergisi $\quad$ RumeliDE Journal of Language and Literature Studies

Osmanağa Mahallesi, Mürver Çiçeği Sokak, No:14/8 Osmanağa Mahallesi, Mürver Çiçeği Sokak, No:14/8

Kadıköy - ISTANBUL / TÜRKIYE 34714 Kadıköy - ISTANBUL / TURKEY 34714

e-posta: editor@rumelide.com e-mail: editor@rumelide.com,

tel: +90 505 7958124, +90 2167730616 phone: +90 505 7958124, +90 2167730616
} 
Ölmez, E. (2015). Vladimir Propp’un Masal Çözümleme Metodu Çerçevesinde "Padişahın Evlatllğı" Masalı Üzerine Bir İnceleme. CBÜ Sosyal Bilimler Dergisi Beşerî Bilimler Sayısı, 13(1), 533-541.

Propp, V. (2001). Masalın Biçimbilimi-Olağanüstü Masalların Yapısı (M. Rifat \& S. Rifat Çev.). 2. Baskı. İstanbul: Om Yayınevi.

Propp, V. (2008). Masaln Biçimbilimi ve Olağanüstü Masalların Dönüşümleri (M. Rifat \& S. Rifat Çev.). İstanbul: Türkiye İş Bankası Kültür Yayınları.

Propp, V. (2011). Masalın Biçim Bilimi (M. Rifat \& S. Rifat Çev.). 11. Baskı. İstanbul: Türkiye İş Bankası Kültür Yayınları.

Radlov, V. V. $(1866,1907)$. Obraztsı Narodnoy Literaturı Turkskih Plemen. Birinci ve dokuzuncu ciltler. Petersburg.

Reichl, K. (1992). Turkic Oral Epic Poetry: Traditions, Forms, Poetic Structure. New York.

Reichl, K. (2002). Türk Boylarmın Destanları (M. Ekici Çev.). Ankara: Türk Dil Kurumu Yayınları.

Samdan, Z. B. (1994). Mir Tuvinskioy Skazki. Tuvinskie Narodne Skazki. Novosibirsk. 10-34.

Şimşek, G. (2012). Los Angeles'da Bir Külkedisi: Propp’a Göre Bir Film Çözümlemesi. Erzincan Üniversitesi Sosyal Bilimler Enstitüsü Dergisi, 2(5), 311-324.

Taube, E. (1978). Tuwinische Volksmärchen. Berlin.

Taube, E. (1994). Skazki i Predeniye Altayskih Tuvintsev. Moskva.

Temel, S. (2005). Propp Metodu ve Bir Karagöz Metnine Uygulanması. Atatürk Üniversitesi Güzel Sanatlar Fakültesi Dergisi, 8, 85-106.

Türker, E. (2013). Masal mı, Yeni Hayat mı? Yeni Hayat Romanını Masalın Biçimbilimine Göre Okuma Denemesi. Millî Folklor, 100, 154-161.

Yalçınkaya, F. (2015). Ayı İslam Batur Masalının Vladimir Propp’un "Masalların Yapısal Çözümlemesi” Yöntemiyle İncelenmesi. Uluslararası Uygur Araştırmaları Dergisi, 5, 33-40.

Zariç, M. (2013). Vladimir Propp'un İşlevler ve Eylem Alanları Modeli Açısından Yaşar Kemal’in Ağrı Dağı Efsanesi Romanı. Hece, 195, 108-117.

Ek.1

\section{Ak-Sagış, Kara Sagış İyi Alışkı}

Ak-Sagış, Kara-Sagış dep iyi alışkı çoraan çüveñ irgin. Kırgan iyelig çüve-dir. Ak-Sagış ak-ak maldıg, Kara-Sagış kara-kara maldıg alışkılar çüveñ irgin.

Bir-le katap kırgan iyezi kidis hevenek daaraaş, şokar argamçı eşkeş olurup bergen. İyezi iyi oglun kel dep algaş:

-Nazın-har uglatkan, al-bot bergedeen, ölüp kaar boop men, ooldarım. Ölüp kaarımga, kidis hevenekke sup algaş, şokar çep argamçıga baglap algaş, hün üner çükçe çorup kaar siler. Çep argamçı üstüp kaarga, meni ol çeringe kaaptar siler. Oon başka söögüm çerge kagbas siler-dep çagıp organ çüveñ irgin.

Çagıp orgaş, avazı ölüp kalgan. İyi alışkı avazın çüktep algaş, çorup-la bergen çüveñ irgin.

Kara-Sagış akızı: “Ölgen sööktü ınça dıka çükteves men”-deeş, çer ara çanıp kelgen çüveñ irgin.

Ak-Sagış hööküy avazın çüktep algaş, çorup-la bergen. Çeje-kaja bolgan çüve ıynaan, çep argamçızı üstüp kalgan. Avazın ol-la çeringe ajaap kaaş, dedir çanıp organ er çüveñ irgin. Bir-le hovu ortuzunga karañgı düne bolgan. Bir köjee baarınga çıdıp algan er çüveñ irgin.

\footnotetext{
Adres Address

RumeliDE Dil ve Edebiyat Araştırmaları Dergisi $\quad$ RumeliDE Journal of Language and Literature Studies

Osmanağa Mahallesi, Mürver Çiçeği Sokkak, No:14/8 $\quad$ Osmanağa Mahallesi, Mürver Çiçeği Sokak, No:14/8

Kadıköy - ISTANBUL / TURKIYE 34714 Kadıköy - ISTANBUL / TURKEY 34714

e-posta: editor@rumelide.com e-mail: editor@rumelide.com,

tel: +90 505 7958124, +90 2167730616 phone: +90 505 7958124, +90 2167730616
} 
Düne kada hey çüve kelgeş, köjee-bile çokşu-la bergen. Hey çüve:

-Baarıñda çıtkan kijini men alır kiji men-deen.

-Berbes men, çerde, hovuda köjee meni kelgen-ne kuş bajımga olurup algaş öder, kurt adaamdan kelgeş oyar, onu çagdatpas buyannıg kijim, berbes men-deen çüveñ irgin.

-“Seen buyanıñ çüü dep? Bir kararga, bir lañ möñü̈n kuzar, ajıñ olla ıynaan”-deeş, hey çüve çorup kaan irgin.

Ak-Sagış erten turup kelgeş, köjeezin adaandan turup algaş, şokar çep argamçızını̃ uju-bile çüktep algaş, çorup-la kaan çüveñ irgin. Aal-çurtunga çedip keerge, Kara-Sagış akızı aalında olurgan çüveñ irgin. İyi alışkı ol-la çeringe çurttap turup bergen.

Kara-Sagış olurgaş:

-Aştangıç çüve-dir, duñmam, mal-maganıñdan ölürüp çiili-deeş, duñmazınıñ Ak-Sagıştıñ mal-maganın ölürüp çip-le çurttap turgan çüveñ irgin. Ta çeje üye bolgan, duñmazınıñ malı-maganı tönüp kalgan.

-Am meeñ malım töngen, akım, seeñ malıñdan çüveden olurup çiili be?-dep, Ak-Sagış aytırgan.

-Mal-maganıñnı çüge ölürüp çip algan sen? Berbes men-deeş, Kara-Sagış kandıg-daa çüvezin berbeyn bargan.

Ak-Sagış köjeezin çüktep algaş, aaldar kezip, dilenip çiir deeş, çorup bergen-dir oo. Köjeezin bir karargala, bir lañ möñgün kuzar, bir lañ möñgünü-bile aaldar kezip çüve dilep çip çorup bergen irgin.

Bir-le çerge kılaştap çoruurga, çadır turgan. Çadırga kire beerge, üş orun çıtkan. Üş orunnuñ ortuzunga ulug tamı kaskaş, çıdıp algan. Inçap çıdırda, bir börü, bir dilgi, hayırakan üjeleen kelgeş, çugaalajı-la bergen.

-Çünü çip tur sen?-dep, dilgiden aytırgan. Dilgi:

-Karatı-haannıñ uruu Aldın-Çuñgulak dañgına aragalap turgaş, bilekteejin kaapkan. Ol bilekteeşti haannıñ aalınıñ hün üner çügünde ulug kara dıttıñ dözünde sup kaan kiji men. Urug oozunga homudaaş aarıy bergen. Lama, ham hürüm-bala çüve tutkaş, ündür oktap turarga, onu çip turar-dır men-dep-tir.

-Kokkaarak, sen çünü kançap çip tur sen?-dep, Kokkaaraktan aytırgan.

-Baza-la ol haan kara suunuñ bajın çüdelip algan, sug bajı bıjartaaş, kañdaan. Mal-magan suksap ölüp turup bergen, ooñ sek-segizinge amırap tur men-deen çüveñ irgin.

-Hayırakan, sen çünü çip tur sen?-dep aytırgannar.

-Bo çadırıvıstıñ hün üner çügünde Bolçaytılıg Bora-Tey kırında aal kodanı deg ulug pöş bar. Ooñ tooruu çerle tönmes, onu çip çorup tur men-deen.

Çaa, ınçangaş erteninde dañ bajı şara-here, daş bajı sarıg-şokar çorda, dilgizi, börüzü, hayırakanı çorup kaap-tırlar oo. Er-daa turup algaş, baza çorup-la bergen.

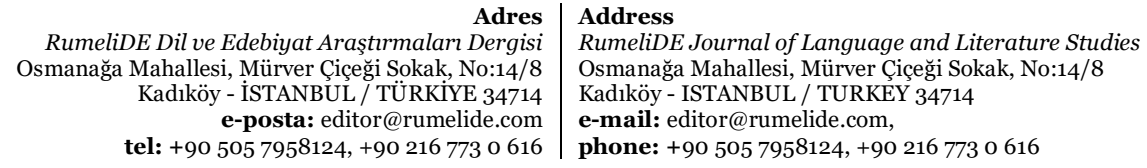

RumeliDE Dil ve Edebiyat Araşturmaları Dergisi , Iürver Çegi Sokak, No.14/8 tel: +90 505 7958124, +902167730616

phone: +90 505 7958124, +90 2167730616 
Ak-Sagış oon çorutkaş, Karatı-haanga çede berip-tir.

-Kayın keldiger, kayı çügürerden ündüñer?-deen, Karatı-haan çüveñ irgin.

-Murnuu çügümden keldim, padarlap çoruur kiji men-deeş, köjeezin olurtur şançıp kaaş, olurup algan er çüveñ irgin.

Haan olurgaş:

-Çañgıs urum aaraan kiji men, şo-tölgeden salıp körüñer-dep dileen çüveñ irgin.

Ak-Sagijıñ tölgelep-le egeleen.

-Kandıg-aaylıg çoor? Ulug-la edin kaggan urug dep düjüp çıdar çüve-dir-deen.

Haan olurgaş hamıtan uluzun çıllırıp-la egeleen.

-Başkı uruumnu ulug edin kaggan dep turar, onu bilgen kiji bar be?- dep aytırıp-la egeleen.

Ulug-daa, biçe-daa amıtanda onu bilir kiji amıtan çerle çañgıs-daa çok bolgan.

Uruu olurgaş:

-Uttupkan-dır men, biletkeejim kaapkan kiji men-dep organ çüveñ irgin.

Ak-Sagış orgaş:

-Ol-dur. Inçaar düjüp çıdır. Aaldıñ hün üner çügünde ulug kara dıt dözünde dep düjüp çıdır-deen.

Haan olurgaş:

-Uruumnu ekirtip alzıñza, baarımnıñ ödü bolgan, karaamnıñ ogu bolgan çañgıs borbak küdee kılıp alır men-dep, çarlık berip olurgan çüveñ irgin.

Höy çonun, hamıtan arı-horaazın algaş, bilekteejin dilep çorup bergen ulus çüveñ irgin. Çoon kara dıttıñ dözünde çede bergeş, dilep-le turup bergen. Bilekteeşti dilep tıp ap-tırlar oo! Urug bilekteejin körüp kaaş, aarı-daa ekirip bargan çüveñ irgin.

Aalınga dedir çanıp kelgen-dirler oo. Haan kiji bodunuñ çarlın küsedir apar. Uruun bergeş, azıraan malınıñ deñ çartınndan, hamıtan çonunuñ deñ çartın bergeş, bir kodan kıldır hondurup algan çüveñ irgin.

Haan:

-Hamıtan mal-magan kırlıp ölüp turup bergen, çüden haytaanıl, çüden hirteenil? Baza şo-tölgeden salıp körem, küdee,-dep organ irgin.

Küdeezi baza-la şo-tölgezin salıp egeleen. Kijiñ baza-la olurup-olurup: "Ulug kara sugnuñ bajı bijartap baksıraan, oon ulug bujar bolgan-dır” dep düjüp çıdar çüve-dir-deen irgin.

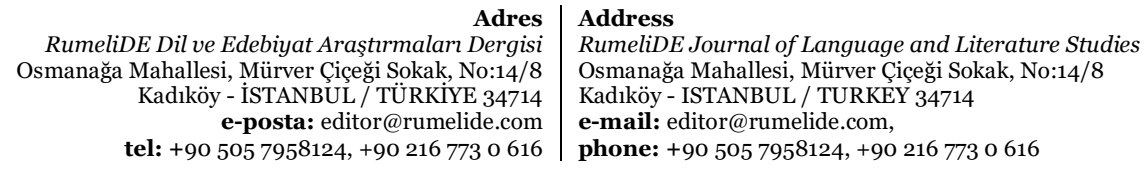


Haan onu dıñnap kaaş, "konçug şınçı kiji bolgay” deeş, kara sugnuñ bajın arıglap-la egeleen irgin. Hoy mıyaa deg çañgıs borbak kara çok kıldır aştap-aştap turda, kara sug-daa delberep batkan çüveñ irgin. Karatı-haannıñ mal-maganı kara sungu işkeş, hençe huragan, hençe anay-daa bürülbesteen turup bergen.

Ak-Sagış bile Karatı-haan iyi katışkı çurttap turup-la turgan çüveñ irgin.

Kara-Sagış akızı bodunuñ hamıtan mal-maganın şuptu ölürüp çigeş, tügerdep-baksıraaş, Ak-Sagış duñmazınıñ soon-izin istep çorup-la bergen çüveñ irgin. Ol-la çoraaş, Ak-Sagıştıñ aal-çurtunga tavarjıp çedip kelgen.

\section{Ak-Sagış duñmazı olurgaş:}

-Konçug-la kiji-dir sen. Bir üyede segeen çüvem bo çüve. Bir kararga, bir lañ möñgün kuzar, mooñ-bile baza amıdırıp körem-deeş, köjeezin ap bergen.

Kara-Sagış köjeezin çüktep algaş, çorup bergen. Bir çerge çede bergeş, kandıg eves deeş şenep kijiñ köjeezin bir kakkan, bir lañ möñün barıp düjüp turar bolgan, "Bir kararga, bir lañ möñgün barıp düjüp turar, kuzup turar, iştinde höy aldın-möñgün bar kulugur-dur. Aar köjeeni çüktep çoraaş kançaar men. Buza şapkaş şuptu aldın-möñgünün ap alıyn”-deeş, köjeeni buza şaap turgan Kara-Sagış-tır. Köjeezi aldın-möñgün-daa çok, kök haya boop çılıp kalgan.

Kara-Sagış kılaştap çorup-la bergen çüveñ irgin. Baza-la Ak-Sagış duñmazınıñ aalınga çede bergen-dir.

\section{Ak-Sagış olurgaş:}

-Köjeeñ kayıl, akıy?-deerge, Kara-Sagıș:

-Hayanı çüktep algaş kılaştap çoruur eves, buza şaap kagdım-deen çüveñ irgin.

Ak-Sagış duñmazı olurgaş:

-Talaar kiji-dir sen. Aaldıñ hün üner çügünde bir çadır bar. Añaa bargaş, oon eki çüveden dıñnap aldeeş, çorudupkan.

Kara-Sagış oon çorutkaş, çadırga çede bergeş, kire beerge, üş orun, ergi tamı bar bolgan. Tamı iştinge çıdıp algan çüveñ irgin.

Dilgi, kokkaarak, hayırakan üjeelee kelgeş, çugaalajı-da bergen.

-Dilgi, sen çünü çip tur sen?-dep aytırgannar.

-Çünü-daa tıppayn tur men. Haannıñ uruunuñ bilekteejin sup kaan kiji men, uştup algaş barıp-tır. Çop konçug udurgu kulugurul-deen.

Kokkaarak, sen çünü çip tur sen?-dep aytırgannar.

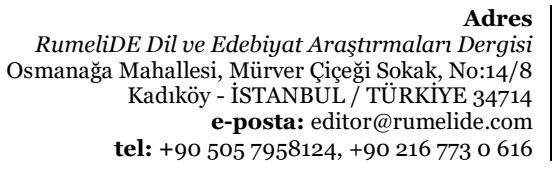

Adres RumeliDE Dil ve Edebiyat Araştırmaları Dergisi
Osmanağa Mahallesi, Mürver Ciçeği Sokak, No:14/8 e-posta: editor@rumelide.com tel: +90 $5057958124,+902167730616$
Address

RumeliDE Journal of Language and Literature Studies

Osmanağa Mahallesi, Mürver Çiçeği Sokak, No:14/8

Kadıköy - ISTANBUL / TURKEY 34714

e-mail: editor@rumelide.com,

phone: +90 $5057958124,+902167730616$ 
-Çünü-daa çiir çüve çok. Kurug çorup tur men. Karatı-haannıñ kara suunuñ bajı hep-henerten araan. Kandıg konçug dayzın iyik, arıglap-aştap kaapkan boldu ışkajıl. Hemniñ hençe anayı-daa ölbes, hençe huraganı-daa ölbes apargan boldu-dep, kokkaarak çugaalaan.

-Hayırakan, sen çünü çip tur sen?-dep aytırgannar.

Hayırakan:

-Mırıñay köñgüs kuruglaan men. Maytak idiktig kiji kelgeş, pöjümnüñ tooruun çip-çip, bo çadır iştinçe kiiir kılaştap kelgen izi bar boldu-deen.

Üjeeleen kattırjıp-la ünüp-türler. Karatı-Sagıjıñ baza kaktırıp düjürüpken. Kara-Sagıştı bilip kaaş, ündür sop algaş, üjeeleen tudup çip kaaptırlar oo.

Ak-Sagış, Karatı-haan iyi katışkı ol-la çeringe oyun oya, çigin çire çurttap çoruy barıp-tır oo!

RumeliDE Dil ve Edebiyat Araştırmaları Dergisi Osmanağa Mahallesi, Mürver Çiçeği Sokak, No:14/8 Kadıköy - İSTANBUL / TÜRKIYE 34714 e-posta: editor@rumelide.com tel: +90 $5057958124,+902167730616$
Address

RumeliDE Journal of Language and Literature Studies Osmanağa Mahallesi, Mürver Çiçeği Sokak, No:14/8

Kadıköy - ISTANBUL / TURKEY 34714

e-mail: editor@rumelide.com

phone: +90 505 7958124, +90 2167730616 